\title{
Postoperative Radiotherapy in Bladder Cancer Patients: 5-Year Institutional Experience of National Cancer Institute, Cairo University
}

\author{
Azza M. Nasr'1, Magda El Mongi', Mamdouh Hagag', Manar M. Moneer ${ }^{3}$, \\ Hisham El Hossieny ${ }^{1 *}$, Azza Taher ${ }^{1}$, Sherif Magdy ${ }^{1}$ \\ ${ }^{1}$ Radiation Oncology Department, National Cancer Institute, Cairo University, Giza, Egypt \\ ${ }^{2}$ Clinical Oncology Department, Faculty of Medicine, Cairo University, Giza, Egypt \\ ${ }^{3}$ Cancer Epidemiology and Biostatistics Department, National Cancer Institute, Cairo University, Giza, Egypt \\ Email: ${ }^{*}$ hisamelhossieny@yahoo.com
}

Received 16 June 2015; accepted 12 July 2015; published 16 July 2015

Copyright (C) 2015 by authors and Scientific Research Publishing Inc.

This work is licensed under the Creative Commons Attribution International License (CC BY). http://creativecommons.org/licenses/by/4.0/

(c) (i) Open Access

\section{Abstract}

Purpose: Adjuvant radiation therapy could reduce loco regional failure, but currently has no defined role because of previously reported morbidity. NCI-Cairo routine work is to give adjuvant PORT for locally advanced bladder carcinoma patients. The aim of this work is to re-evaluate this protocol regarding its effect on prognosis and complications. Patients and Method: A retrospective study included 208 patients with pathologically proven bladder cancer who presented to the NCI, Cairo University from 2007-2011. All of them underwent RC with bilateral PLND followed by conventional post-operative radiotherapy in 2 - 6 weeks after surgery for 5000 cGy in 25 fractions, over 5 weeks using 2D technique. Analysis of data from their files was done for the treatment results, prognostic factors and complications. Results: Three years overall survival (OS) and disease free survival (DFS) for the whole group was $\sim 60 \%$, and $54 \%$ respectively in favour of the female gender, non-smokers, Squamous cell carcinoma patients, low grade tumours (grade 1 and 2) negative margins, N0, pT2b and early stage group showed the best prognoses. The 3 years metastases free survival (MFS) was $\sim 71 \%$. Only four factors showed a significant relation with the MFS which were the grade, LN status, T-stage and group staging. The local recurrence rate (LRC) at 2 years for the whole group was $\sim 95 \%$ and $94 \%$ at 3 years. Only surgical margin status and extent of LN dissection had a significant impact on the LRC. Conclusions: Adjuvant radiotherapy shows sustained improvement in the loco regional control, and should be recommended for patients with locally advanced disease especially those with less than 10 dissected lymph nodes and those with positive

\footnotetext{
${ }^{*}$ Corresponding author.
} 
margins.

Keywords

Bladder Cancer, Radiotherapy, Pelvic Irradiation

\section{Introduction}

More than 350,000 new cases of bladder cancer are diagnosed worldwide each year; the vast majority ( $>90 \%)$ of these are transitional cell carcinomas (TCC) [1] [2]. Local disease control is a clinically relevant challenge in the management of muscle invasive bladder carcinoma. Worldwide, radical cystectomy (RC) and pelvic lymphadenectomy (PLND) has been the cornerstone treatment for muscle invasive TCC [3]. Five-year survival after radical cystectomy for clinically localised muscle invasive bladder cancer is only approximately $50 \%$ [4].

A meta-analysis of randomized controlled trials with or without platinum-based chemotherapy following local therapy (usually RC) showed that $25.6 \%$ of patients with chemotherapy had locoregional recurrence as a first event with or without synchronous distant metastasis [5]. Reducing locoregional recurrences could potentially improve disease-free survival. Also some found that local-regional recurrence was an independent prognostic variable predicting distant metastasis (DM) [6] [7].

In an attempt to increase locoregional control, the use of postoperative radiotherapy (PORT) was explored decades ago and demonstrated robust local control [8]-[10] but serious gastrointestinal toxicity, using pre-1980s RT techniques discouraged its use [9] [11].

Improvements in targeting radiation and the increasingly recognized local-regional failure as a more significant problem than was previously appreciated have rekindled interest in adjuvant RT for high-risk patients [12] [13].

Postoperative radiotherapy has the advantage of dealing with microscopic cells that are easier to sterilize. It allows better identification of the group of patients that may benefit from such adjuvant therapy.

Previous results of our own centre showed significant improvement in local control using PORT for locally advanced bladder carcinoma patients [8] [14]. Depending on these results, the routine work at National Cancer Institute (NCI), Cairo University (CU) is to give PORT for bladder cancer patients with T-stage $\geq \mathrm{pT} 2 \mathrm{~b}$, node positive cases and positive surgical margin. This study was conducted to re-evaluate this protocol regarding its effect on prognosis and complications.

\section{Patients and Method}

This retrospective study included 208 patients with pathologically proven bladder cancer who presented to the radiotherapy department, NCI, CU from January 2007 till December 2011. All of them underwent RC with bilateral PLND followed by adjuvant external beam radiotherapy. All of the 208 patients, included in the analysis completed their course of radiation.

The treatment volume included the urinary bladder bed and pelvic lymph nodes.

- Upper margin: either at the level between sacral vertebra one and two (83 patients) or between lumbar vertebra five and the first sacral vertebra (125 patients).

- Lower margin: at the inferior border of obturator foramena. In cases of prostatic invasion, the inferior border extended downwards to the lower border of the ischium.

- Lateral border: lies $1.5 \mathrm{~cm}$ outside the bony pelvic brim.

- The anterior border of the lateral field lies just in front of the symphysis pubis.

- The posterior border stops at the junction of anterior one third and posterior two thirds of the rectal circumference or the junction of the first and second sacral vertebrae.

- Field arrangement: All patients were treated isocenterically through three fields (one anterior and two lateral wedged fields) or four fields (box technique).

- A homogenous distribution to the treatment volume with maximum deviation of $+7 \%$ and $-5 \%$ and a minimum dose to the rectum have to be insured.

- Treatment was given on a 6 MV Linear accelerator. 
- Dose: conventional post-operative radiotherapy in 2 - 6 weeks after surgery for 5000 cGy in 25 fractions, over 5 weeks using 2D technique (Figure 1, Figure 2).

- Toxicity Reporting: The RTOG/EORTC Radiation Toxicity Grading was used to score acute radiation ( $\leq 90$ days) toxicities while toxicities appearing or persisting beyond 90 days from start of RT were documented as late radiation toxicities [15].

\subsection{Assessment}

- Overall survival (OS): the period started from the date of diagnosis until patient death or time of last follow up.

- Disease free survival (DFS): the period started from the date of cystectomy until the first appearance of relapse, whether this relapse was local or systemic or the last date of follow up.

- Local control period is the time started from the date of cystetomy until appearance of locoregional recurrence, or the day of reporting. Patients who developed distant metastasis without local recurrence considered censored.

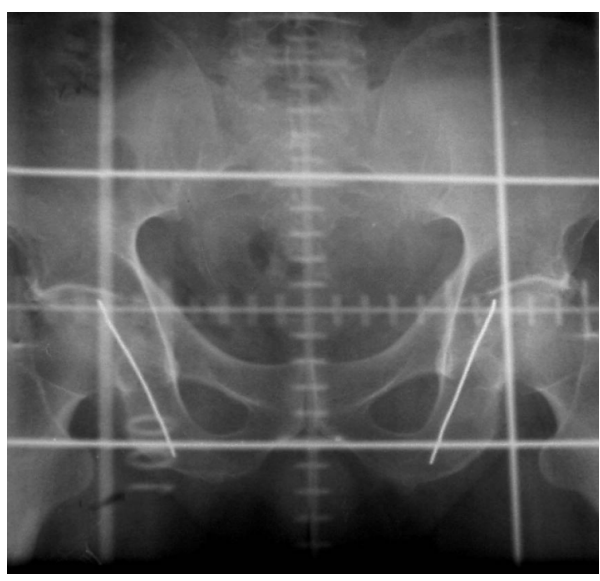

Figure 1. Simulator film for the anterior field and showing a femoral head shields.

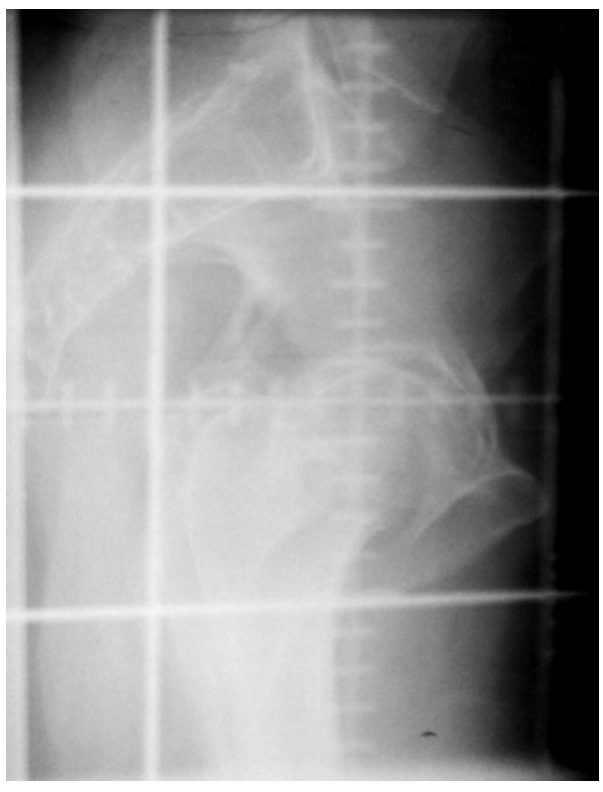

Figure 2. Simulator film for the lateral field. 
- Distant metastasis-free survival time in the period from cystectomy until first appearance of dissemination or time of last follow up in those who did not develop distant metastasis. Patients who developed local recurrence without systemic dissemination are considered censored.

\subsection{Statistical Methods}

Data was analyzed using IBM SPSS advanced statistics version 20 (SPSS Inc., Chicago, IL). Survival analysis was done using Kaplan-Meier method and comparison between two survival curves was done using log-rank test. All tests were two-tailed. A p-value $<0.05$ was considered significant [16].

\section{Results}

Out of the 208 eligible bladder cancer patient, 158 were males (76\%) and 50 females (24\%), with a male to female ratio of 3:1. The mean age was $56 \pm 7.4$ years (range: 26 - 77 years). Patient’s characteristics are shown in Table 1.

Transitional cell carcinoma constitutes about $52.4 \%$ of cases while the remaining is SCC. Low grade tumours (grade 1 and 2) were more common (65.4\%) than high grade tumours (34.6\%). About 82\% of SCC patients had low grade tumours compared to $50 \%$ in the TCC group of patients. Only $20 \%$ in the SCC group were LN positive compared to $32 \%$ of TCC patients (Table 2).

The pathological p3b stage represented the majority of cases (56.3\%). Seventy four percent of patients have negative LN status while the rest (26\%) had positive node. The surgical margin was positive in 15 patients only (7.2\%).

\subsection{Treatment Toxicity}

\subsubsection{Acute Complications According to RTOG}

\section{- Lower GI symptoms}

One hundred forty eight patients ( 71\%) had lower GI symptoms. Eighty one patients ( $\sim 55 \%)$ complained of grade 1 symptom and 63 patients ( 43\%) complained of grade 2 symptoms (Figure 3). Only 4 patients ( 3\%) suffered from bleeding per rectum.

\section{- Skin reactions}

Nine patients ( 4\%) experienced skin toxicity. Grade 1 reactions were present in 2 patients while grade 2 reactions were present in 7 patients (Figure 3).

\section{- Relation of the upper field border with acute toxicity}

One hundred and twenty five patients were treated with an upper border of L5-S1 while the rest (83 patients) treated with S1-S2. The lower GI symptoms were present in 91 patients ( 73\%) treated with L5-S1 as an upper border. Grade 1 constituted $56 \%$ of cases while grade 2 was $44 \%$. On the other hand 57 patients out of 83 ( 69\%) treated with S1-S2 as an upper border complained of GI symptoms with grade 1 and 2 of $57 \%$ and $43 \%$ respectively. These results were not found to be statistically significant.

\section{Late Toxicity:}

From a total of 208 patients, 50 patients (24\%) suffered from late reactions: 20 patients (40\%) complained of bilateral lower limb oedema, 21 patients (42\%) presented by ureteric stricture, 3 patients (6\%) complained of scrotal swelling and 6 patients (12\%) suffered from intestinal obstruction necessitating surgical referral (Two

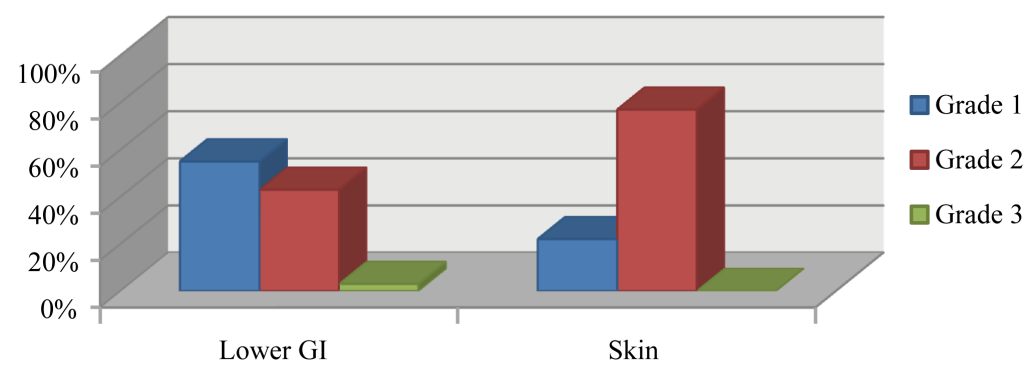

Figure 3. Grades of acute radiotherapy complications. 
Table 1. Patient's characteristics $(n=208)$.

\begin{tabular}{|c|c|c|c|}
\hline \multicolumn{2}{|c|}{ Characteristics } & \multirow{2}{*}{$\begin{array}{c}\text { Number } \\
208\end{array}$} & \multirow[t]{2}{*}{ Percentage (\%) } \\
\hline Total & 208 & & \\
\hline \multirow{2}{*}{ Age group } & $<60$ & 128 & 61.5 \\
\hline & $\geq 60$ & 80 & 38.5 \\
\hline \multirow{2}{*}{ Gender } & Males & 158 & 76 \\
\hline & Females & 50 & 24 \\
\hline \multirow{2}{*}{ Smoking } & Yes & 92 & 55.8 \\
\hline & No & 116 & 44.2 \\
\hline \multirow{3}{*}{ PS } & 1 & 144 & 69.2 \\
\hline & 2 & 59 & 28.4 \\
\hline & 3 & 5 & 2.4 \\
\hline \multirow{2}{*}{ Pathology } & SQ & 99 & 47.6 \\
\hline & TCC & 109 & 52.4 \\
\hline \multirow{3}{*}{ Grade } & 1 & 10 & 4.8 \\
\hline & 2 & 126 & 60.6 \\
\hline & 3 & 72 & 34.6 \\
\hline \multirow{2}{*}{ SM } & Positive & 15 & 7.2 \\
\hline & Negative & 193 & 92.8 \\
\hline \multirow{2}{*}{ LN dissection } & $<10$ & 71 & 34.1 \\
\hline & $\geq 10$ & 137 & 65.9 \\
\hline \multirow{2}{*}{ LN } & Negative & 153 & 74 \\
\hline & Positive & 55 & 26 \\
\hline \multirow{4}{*}{ T-stage } & $2 \mathrm{~b}$ & 54 & 26 \\
\hline & За & 16 & 7.7 \\
\hline & $3 b$ & 117 & 56.3 \\
\hline & $4 a$ & 21 & 10.1 \\
\hline \multirow{3}{*}{$\mathrm{N}$-stage } & No & 153 & 73.6 \\
\hline & N1 & 21 & 10.1 \\
\hline & N2 & 34 & 16.4 \\
\hline \multirow{3}{*}{ Stage } & 2 & 46 & 22.1 \\
\hline & 3 & 106 & 51 \\
\hline & 4 & 56 & 26.9 \\
\hline
\end{tabular}

Table 2. Tumor grade and LN status of TCC and SCC cases.

\begin{tabular}{rccccc}
\hline & No. & LN +ve & LN -ve & Low grade & High grade \\
\hline TCC & 109 & $35(32.1 \%)$ & 74 & $55(50.4 \%)$ & $54(49.5 \%)$ \\
SCC & 99 & $20(20.2 \%)$ & 79 & $81(81.8 \%)$ & $18(18.2 \%)$
\end{tabular}


patients were treated conservatively, 2 patients underwent surgical exploration, 1 patient died and 1 patient had lost follow up) (Figure 4).

\section{- Relation of the upper field border with late toxicity}

Patients with L5-S1 as an upper border had higher late complications than those with S1-S2 as an upper border. In the L5-S1 group, 30/125 patients (24\%) had late complications which was represented by lower limb edema in 12 patients, ureteric stricture in 14 patients and intestinal obstruction in 4 patients. As for the S1-S2 group, 20/83 patients (24\%) had late complications which was represented by lower limb oedema in 8 patients, ureteric stricture in 7 patients, ureteric stricture in 3 patients and intestinal obstruction in 2 patients only. None of this relation proved to be statistically significant (Figure 4).

\subsubsection{Treatment Outcomes}

The median follow up period was 22 months, ranging from 8 months to 7 years and 3 months.

1) Overall Survival

The 2-year OS for the whole group was $~ 69 \%$ and the 3-year OS was $~ 60 \%$ (Table 3).

All factors were statistically significant except age, performance status and number of lymph node dissected (Figure 5).

\section{2) Disease Free Survival}

The DFS among all 208 patients was $~ 65 \%$ at 2 years and $~ 54 \%$ at 3 years. Patients' age, performance status and number of LN dissection had no significant impact on DFS (Table 4 and Figure 6).

\section{3) Metastasis Free Survival (MFS)}

The 2-year MFS for all treated patients was $78 \%$ and the 3 years MFS was $\sim 71 \%$. Only four factors showed a significant relation with the MFS which are the grade, LN status, T-stage and group staging (Table 5 and Figure 7).

\section{4) Loco Regional Control (LRC)}

The LRC at 2 years for the whole group was $~ 95 \%$ and $94 \%$ at 3 years. Only surgical margin status and extent of LN dissection had a significant impact on the LRC (Table 6 and Figure 8, Figure 9).

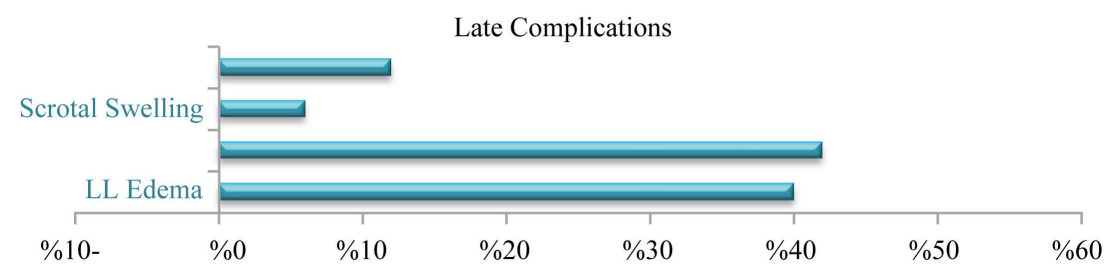

Figure 4. Column demonstrating the frequency of late radiotherapy complication.

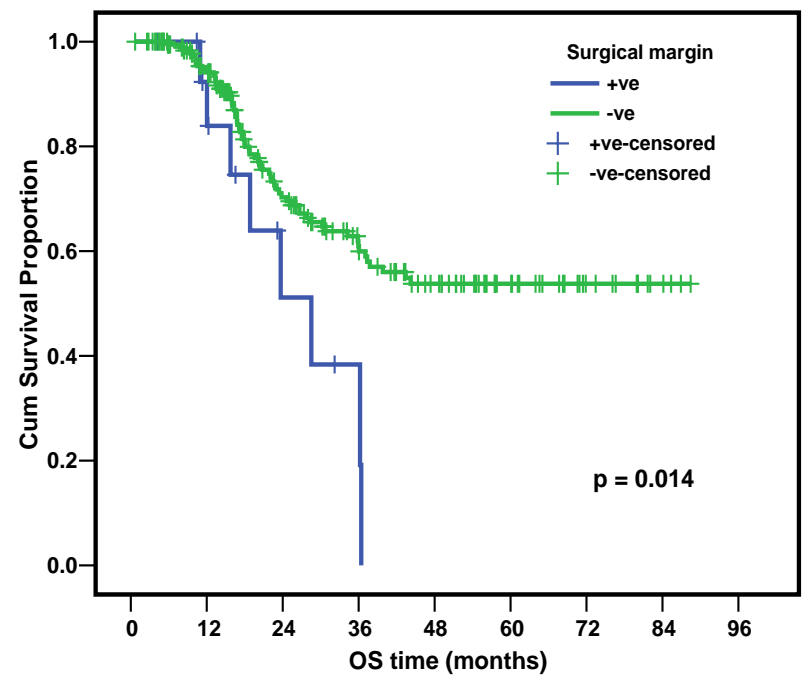

Figure 5. Impact of the surgical margin on OS. 
Table 3. Overall survival of bladder cancer cases and its relation to different factors.

\begin{tabular}{|c|c|c|c|c|c|}
\hline & No. & $\begin{array}{c}\text { Cum survival at } \\
2 \text { yrs \% }\end{array}$ & $\begin{array}{c}\text { Cum survival at } \\
3 \text { yrs \% }\end{array}$ & 5 yrs & P-value \\
\hline Whole group & 208 & 69.1 & 59.5 & 50.9 & \\
\hline \multicolumn{6}{|l|}{ Age group } \\
\hline$<60$ & 128 & 71.5 & 62.9 & 54.8 & \multirow{2}{*}{0.371} \\
\hline$\geq 60$ & 80 & 66 & 55 & 45.6 & \\
\hline \multicolumn{6}{|l|}{ Sex } \\
\hline Males & 158 & 63.8 & 53.3 & 43 & \multirow{2}{*}{0.002} \\
\hline Females & 50 & 86.4 & 79.1 & 75.4 & \\
\hline \multicolumn{6}{|l|}{ Smoking } \\
\hline Yes & 92 & 65.3 & 52.8 & 38.8 & \multirow{2}{*}{0.042} \\
\hline No & 116 & 71.9 & 64.8 & 61.2 & \\
\hline \multicolumn{6}{|l|}{ PS } \\
\hline 1 & 144 & 71.4 & 64.8 & 55.2 & \multirow{2}{*}{0.197} \\
\hline $2 \& 3$ & 64 & 63.3 & 49.9 & 40.6 & \\
\hline \multicolumn{6}{|l|}{ Pathology } \\
\hline SQ & 99 & 77.7 & 68.2 & 62.6 & \multirow{2}{*}{0.020} \\
\hline TCC & 109 & 61.5 & 51.6 & 39.5 & \\
\hline \multicolumn{6}{|l|}{ Grade } \\
\hline Low (1 \& 2) & 136 & 75.9 & 66.4 & 59.2 & \multirow{2}{*}{0.003} \\
\hline High (3) & 72 & 56 & 46.1 & 34.4 & \\
\hline \multicolumn{6}{|l|}{ SM } \\
\hline Positive & 15 & 51.1 & 38.4 & 0 & \multirow{2}{*}{0.014} \\
\hline Negative & 193 & 70.3 & 60.9 & 53.8 & \\
\hline \multicolumn{6}{|l|}{ LN dissection } \\
\hline$<10$ & 71 & 68.3 & 57.4 & 48.2 & \multirow{2}{*}{0.668} \\
\hline$\geq 10$ & 137 & 69.6 & 60.6 & 52.3 & \\
\hline \multicolumn{6}{|l|}{$\mathbf{L N}$} \\
\hline +ve & 55 & 52.2 & 40.7 & 36.2 & \multirow{2}{*}{0.005} \\
\hline- ve & 153 & 74.6 & 66.5 & 55.5 & \\
\hline \multicolumn{6}{|l|}{ T-stage } \\
\hline pT2b & 54 & 80.2 & 73 & 73 & \multirow{4}{*}{0.011} \\
\hline рТЗа & 16 & 80.8 & 61.2 & 32.6 & \\
\hline pT3b & 117 & 65.4 & 57.6 & 48 & \\
\hline T4a & 21 & 47.2 & 28.3 & 18.9 & \\
\hline \multicolumn{6}{|l|}{ N-stage } \\
\hline No & 153 & 74.6 & 65.4 & 55.5 & \multirow{3}{*}{0.02} \\
\hline N1 & 21 & 51 & 44.6 & 35.7 & \\
\hline N2 & 34 & 52.6 & 36.1 & 36.1 & \\
\hline \multicolumn{6}{|l|}{ Stage } \\
\hline 2 & 46 & 85.2 & 81.3 & 81.3 & \multirow{3}{*}{0.001} \\
\hline 3 & 106 & 69.9 & 60.2 & 45.3 & \\
\hline 4 & 56 & 53.6 & 42.6 & 38.4 & \\
\hline
\end{tabular}


Table 4. Disease free survival of bladder cancer cases and its relation to different factors.

\begin{tabular}{|c|c|c|c|c|c|}
\hline & No. & $\begin{array}{c}\text { Cum survival at } \\
2 \text { yrs } \%\end{array}$ & $\begin{array}{c}\text { Cum survival at } \\
3 \text { yrs \% }\end{array}$ & 5 yrs \% & P-value \\
\hline Whole group & 208 & 65.2 & 53.9 & 52.9 & \\
\hline \multicolumn{6}{|l|}{ Age group } \\
\hline$<60$ & 128 & 70 & 56.7 & 56.7 & \multirow{2}{*}{0.455} \\
\hline$\geq 60$ & 80 & 58.9 & 50.6 & 47.6 & \\
\hline \multicolumn{6}{|l|}{ Sex } \\
\hline Males & 158 & 59.2 & 46.6 & 45.1 & \multirow{2}{*}{0.001} \\
\hline Females & 50 & 84.8 & 77.4 & 77.4 & \\
\hline \multicolumn{6}{|l|}{ Smoking } \\
\hline Yes & 92 & 59.7 & 44.1 & 41.7 & \multirow{2}{*}{0.049} \\
\hline No & 116 & 69.4 & 61.8 & 61.8 & \\
\hline \multicolumn{6}{|l|}{ PS } \\
\hline 1 & 144 & 68.9 & 57.8 & 57.8 & \multirow{2}{*}{0.116} \\
\hline $2 \& 3$ & 64 & 55.8 & 44.5 & 41.1 & \\
\hline \multicolumn{6}{|l|}{ Pathology } \\
\hline SQ & 99 & 72.9 & 64.1 & 64.1 & \multirow{2}{*}{0.019} \\
\hline TCC & 109 & 58.3 & 44.6 & 42 & \\
\hline \multicolumn{6}{|l|}{ Grade } \\
\hline Low & 136 & 72.7 & 61.7 & 60.2 & \multirow{2}{*}{0.002} \\
\hline High & 72 & 50.4 & 38.7 & 38.7 & \\
\hline \multicolumn{6}{|l|}{ SM } \\
\hline Positive & 15 & 48.5 & 0 & 0 & \multirow{2}{*}{0.005} \\
\hline Negative & 193 & 66.4 & 56.4 & 55.3 & \\
\hline \multicolumn{6}{|l|}{ LN dissection } \\
\hline$<10$ & 71 & 62.1 & 56.2 & 52.7 & \multirow{2}{*}{0.657} \\
\hline$\geq 10$ & 137 & 66.7 & 53.3 & 53.3 & \\
\hline \multicolumn{6}{|l|}{$\mathbf{L N}$} \\
\hline Positive & 55 & 55.9 & 39.5 & 39.5 & \multirow{2}{*}{0.025} \\
\hline Negative & 153 & 68.6 & 58.6 & 57.2 & \\
\hline \multicolumn{6}{|l|}{ T-stage } \\
\hline pT2b & 54 & 78.6 & 74.7 & 74.7 & \multirow{4}{*}{0.009} \\
\hline рТЗа & 16 & 72.7 & 42.4 & 28.3 & \\
\hline pT3b & 117 & 61.4 & 51.3 & 51.3 & \\
\hline T4a & 21 & 42.7 & 21.4 & 21.4 & \\
\hline \multicolumn{6}{|l|}{ N-stage } \\
\hline No & 153 & 68.6 & 58.6 & 58.6 & \multirow{3}{*}{0.074} \\
\hline N1 & 21 & 51.9 & 37.9 & 37.9 & \\
\hline N2 & 34 & 59.1 & 40.5 & 40.5 & \\
\hline \multicolumn{6}{|l|}{ Stage } \\
\hline 2 & 46 & 83.3 & 83.3 & 83.3 & \multirow{3}{*}{0.003} \\
\hline 3 & 106 & 62.1 & 48.3 & 46.5 & \\
\hline 4 & 56 & 57.4 & 41.8 & 41.8 & \\
\hline
\end{tabular}


Table 5. Metastasis free survival of bladder cancer cases and its relation to different factors.

\begin{tabular}{|c|c|c|c|c|c|}
\hline & No. & $\begin{array}{c}\text { Cum survival at } \\
2 \text { yrs \% }\end{array}$ & $\begin{array}{c}\text { Cum survival at } \\
3 \text { yrs \% }\end{array}$ & 5 yrs \% & P-value \\
\hline Whole group & 208 & 78.2 & 70.7 & 70.7 & \\
\hline \multicolumn{6}{|l|}{ Age group } \\
\hline$<60$ & 128 & 77.5 & 70.4 & 70.4 & \multirow{2}{*}{0.591} \\
\hline$\geq 60$ & 80 & 79.9 & 71.5 & 71.5 & \\
\hline \multicolumn{6}{|l|}{ Sex } \\
\hline Males & 158 & 74.6 & 65.5 & 65.5 & \multirow{2}{*}{0.29} \\
\hline Females & 50 & 89.5 & 85.6 & 85.6 & \\
\hline \multicolumn{6}{|l|}{ Smoking } \\
\hline Yes & 92 & 72.4 & 59.9 & 59.9 & \multirow{2}{*}{0.072} \\
\hline No & 116 & 82.5 & 78.5 & 78.5 & \\
\hline \multicolumn{6}{|l|}{ PS } \\
\hline 1 & 144 & 80 & 71.3 & 71.3 & \multirow{2}{*}{0.506} \\
\hline $2 \& 3$ & 64 & 73.8 & 69.4 & 69.4 & \\
\hline \multicolumn{6}{|l|}{ Pathology } \\
\hline SQ & 99 & 80.1 & 76.1 & 76.1 & \multirow{2}{*}{0.278} \\
\hline TCC & 109 & 76.3 & 64.5 & 64.5 & \\
\hline \multicolumn{6}{|l|}{ Grade } \\
\hline Low & 136 & 83.8 & 79.5 & 79.5 & \multirow{2}{*}{0.002} \\
\hline High & 72 & 66.3 & 50.9 & 50.9 & \\
\hline \multicolumn{6}{|l|}{ SM } \\
\hline Positive & 15 & 77.1 & 77.1 & 77.1 & \multirow{2}{*}{0.504} \\
\hline Negative & 193 & 78.7 & 70.8 & 70.8 & \\
\hline \multicolumn{6}{|l|}{ LN dissection } \\
\hline$<10$ & 71 & 77 & 72.9 & 72.9 & \multirow{2}{*}{0.852} \\
\hline$\geq 10$ & 137 & 78.6 & 70 & 70 & \\
\hline \multicolumn{6}{|l|}{$\mathbf{L N}$} \\
\hline +ve & 55 & 70.8 & 60.3 & 60.3 & \multirow{2}{*}{0.053} \\
\hline- ve & 153 & 80.9 & 74 & 74 & \\
\hline \multicolumn{6}{|l|}{ T-stage } \\
\hline pT2b, pT3a & 70 & 92.7 & 89.3 & 89.3 & \multirow{2}{*}{0.0005} \\
\hline pT3b, T4 & 138 & 70 & 60.6 & 60.6 & \\
\hline \multicolumn{6}{|l|}{ Stage } \\
\hline 2 & 46 & 91.2 & 91.2 & 91.2 & \multirow{3}{*}{0.019} \\
\hline 3 & 106 & 76 & 66 & 66 & \\
\hline 4 & 56 & 72 & 62 & 62 & \\
\hline \multicolumn{6}{|l|}{ N-stage } \\
\hline No & 153 & 80.9 & 74 & 74 & \multirow{3}{*}{0.154} \\
\hline N1 & 21 & 69.5 & 57.9 & 57.9 & \\
\hline N2 & 34 & 72.4 & 62 & 62 & \\
\hline
\end{tabular}


Table 6. LRC of 208 bladder cancer cases and its relation to different factors.

\begin{tabular}{|c|c|c|c|c|c|}
\hline & No. & $\begin{array}{c}\text { Cum survival at } \\
2 \text { yrs\% }\end{array}$ & $\begin{array}{c}\text { Cum survival at } \\
3 \text { yrs } \%\end{array}$ & 5 yrs & P-value \\
\hline Whole group & 208 & 94.7 & 93.5 & 93.5 & \\
\hline \multicolumn{6}{|l|}{ Age group } \\
\hline$<60$ & 128 & 94.3 & 92.4 & 92.4 & \multirow{2}{*}{0.492} \\
\hline$\geq 60$ & 80 & 95.3 & 95.3 & 95.3 & \\
\hline \multicolumn{6}{|l|}{ Sex } \\
\hline Males & 158 & 95.2 & 93.3 & 93.3 & \multirow{2}{*}{0.735} \\
\hline Females & 50 & 93 & 93 & 93 & \\
\hline \multicolumn{6}{|l|}{ Smoking } \\
\hline Yes & 92 & 97.6 & 97.6 & 97.6 & \multirow{2}{*}{0.125} \\
\hline No & 116 & 92.4 & 90.5 & 90.5 & \\
\hline \multicolumn{6}{|l|}{ PS } \\
\hline 1 & 144 & 94.2 & 94.2 & 94.2 & \multirow{2}{*}{0.899} \\
\hline $2 \& 3$ & 64 & 95.9 & 90.9 & 90.9 & \\
\hline \multicolumn{6}{|l|}{ Pathology } \\
\hline SQ & 99 & 95 & 95 & 95 & \multirow{2}{*}{0.628} \\
\hline TCC & 109 & 94.4 & 91.8 & 91.8 & \\
\hline \multicolumn{6}{|l|}{ Grade } \\
\hline Low & 136 & 95.4 & 93.8 & 93.8 & \multirow{2}{*}{0.590} \\
\hline High & 72 & 93.3 & 93.3 & 93.3 & \\
\hline \multicolumn{6}{|l|}{ SM } \\
\hline Positive & 15 & 76.6 & 76.6 & 76.6 & \multirow{2}{*}{0.001} \\
\hline Negative & 193 & 96.1 & 94.8 & 94.8 & \\
\hline \multicolumn{6}{|l|}{ LN dissection } \\
\hline$<10$ & 71 & 89.5 & 89.5 & 89.5 & \multirow{2}{*}{0.052} \\
\hline$\geq 10$ & 137 & 97.3 & 95.5 & 95.5 & \\
\hline \multicolumn{6}{|l|}{$\mathbf{L N}$} \\
\hline +ve & 55 & 92.6 & 92.6 & 92.6 & \multirow{2}{*}{0.658} \\
\hline- ve & 153 & 95.3 & 93.8 & 93.8 & \\
\hline \multicolumn{6}{|l|}{ Stage } \\
\hline 2 & 46 & 94.9 & 94.9 & 94.9 & \multirow{3}{*}{0.924} \\
\hline 3 & 106 & 95.3 & 93 & 93 & \\
\hline 4 & 56 & 92.8 & 92.8 & 92.8 & \\
\hline \multicolumn{6}{|l|}{ T-stage } \\
\hline $2 b, 3 a$ & 70 & 96.7 & 93.7 & 93.7 & \multirow{2}{*}{0.677} \\
\hline $3 b, 4$ & 138 & 93.4 & 93.4 & 93.4 & \\
\hline \multicolumn{6}{|l|}{ Upper Border } \\
\hline L5-S1 & 125 & 93.9 & 92 & 92 & \multirow{2}{*}{0.480} \\
\hline S1-S2 & 83 & 95.8 & 95.8 & 95.8 & \\
\hline
\end{tabular}




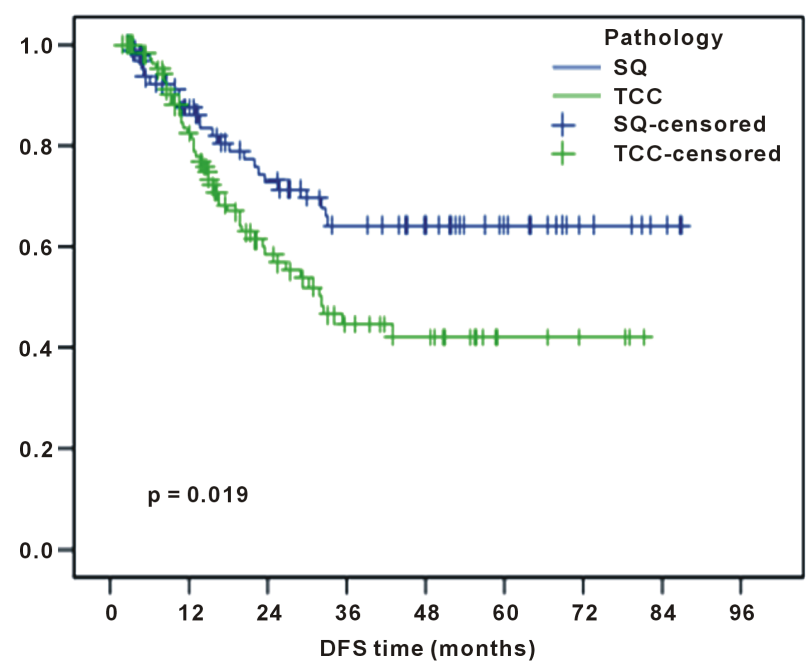

Figure 6. Impact of pathological type on DFS.

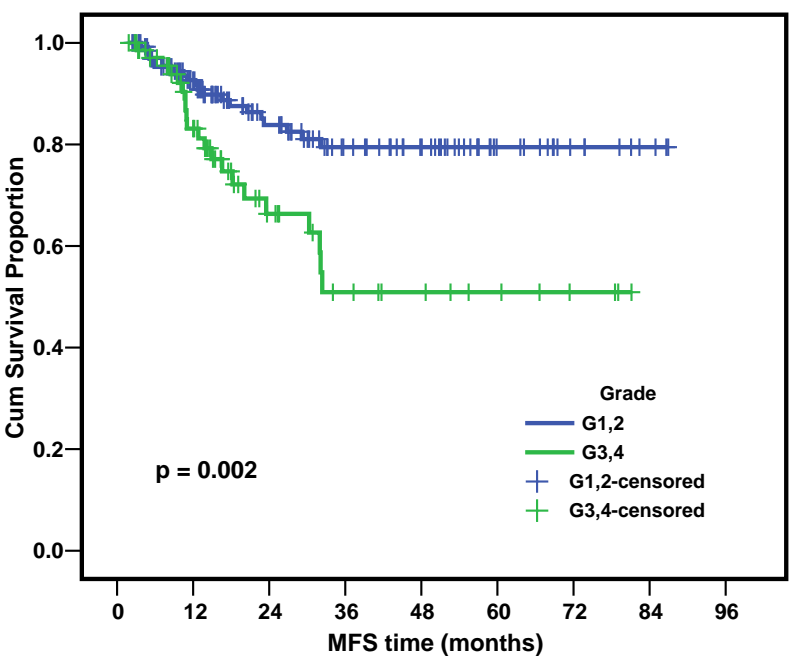

Figure 7. Impact of tumor grade on MFS.

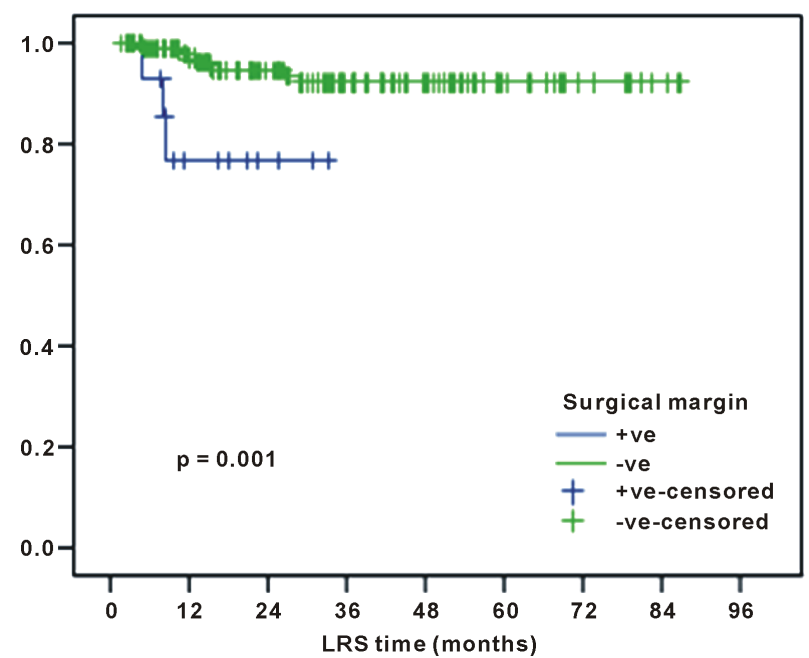

Figure 8. Impact of surgical margin status on LRC. 


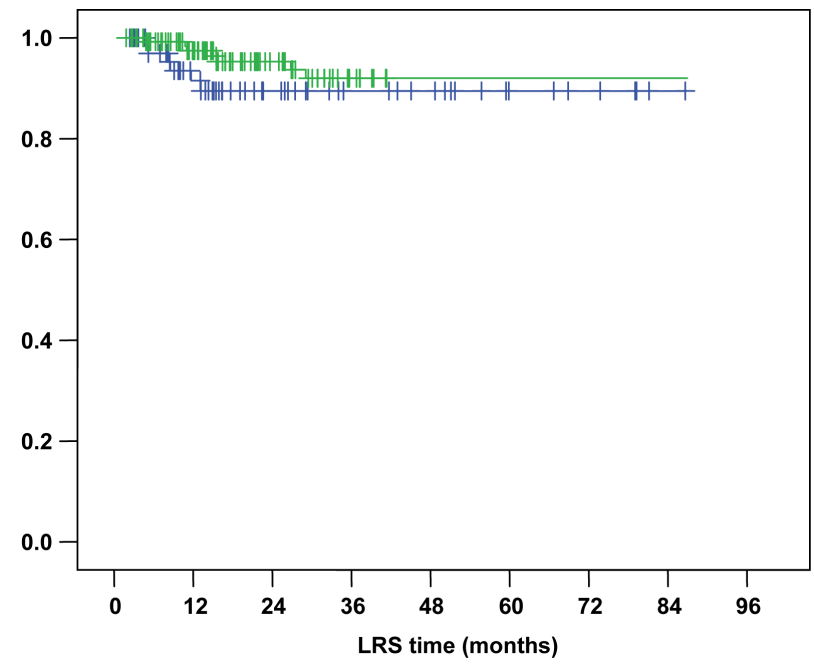

Figure 9. Impact of the extent of nodal dissection on LRC.

\section{Discussion}

Bladder cancer is one of the commonest malignancies in Egypt [17]. In this retrospective study, 208 patients with bladder cancer presenting to the radiotherapy department at NCI Cairo Egypt, were reviewed. All underwent RC and received PORT. Several epidemiological and clinical factors were studied as well as prognostic factors influencing local tumour control, distant disease failure in addition to survival.

Bladder cancer is more common in males than in females with a 3:1 ratio. This was affirmed in our study with males representing 76\% of cases. Bladder cancer occurs mainly in older people. About 9 out of 10 people with this cancer are over the age of 55. The average age at the time of diagnosis is 73 [18]. In the current study, younger age was recorded with a mean of $56 \pm 7.4$ years with a median age of 56 years.

Transitional cell carcinoma represents $90 \%$ of bladder cancer with low incidence of SCC and adenocarcinoma. A time trend retrospective analysis on 9843 patients treated by cystectomy at NCI, Cairo during the years 19702007 was reported. Bilharzial association dropped from 82\% to 55\%. There was a significant rise of transitional cell carcinomas (TCC) from $16 \%$ to $66 \%$ becoming at present the most common tumour type, with a significant decrease in SCC from $76 \%$ to $28 \%$ [19]. This was also affirmed in the current study with TCC representing $52.4 \%$ while SCC represents $47.6 \%$.

The effect of patients' sex on survival is controversial. A study by Tracey et al. 2009 [20] investigating factors that influenced survival in 17,923 cases retrospectively showed that males have better survival than females by $11 \%$. Several studies also demonstrated inferior survival in females compared to males [21]-[23]. On the contrary, the present study demonstrated better 5 year survival for females with an OS of $75 \%$ versus $43 \%$ for males. Similarly, the DFS was more favourable in females, representing $77 \%$ at 5 years versus $45 \%$ in males. This result may be attributed to the fact that only $18 \%$ of female cases in our study had LN involvement compared to $28 \%$ in males, which may have resulted in more inferior survival rates among these patients.

A study of 460 patients who underwent RC between the years of 1991-2011 was analysed retrospectively. The 5 years DFS rates were 58\% in the TCC and 39\% in the SCC group. Although the DFS among TCC cases was better than in SCC, both pathologic types had almost similar prognosis when compared stage by stage. Also, SCC cases were diagnosed at advanced stages of the disease. The incidence of organ-confined, extra vesical, lymph node-positive disease in TCC vs. SCC cases was $49 \%$ vs. $32 \%$, $29 \%$ vs. $32 \%$, $22 \%$ vs. $36 \%$, respectively [24]. A study at NCI, Cairo reported improvement in the 5 year local control rates after the addition of PORT to $\mathrm{RC}$, which in turn was reflected on the DFS. This improvement was constant for all histologic tumour types [8]. In the current study, the 5 year OS was $63 \%$ and $40 \%$ for SCC and TCC respectively, while the 5 year DFS was 64\% and $42 \%$. This shows a significantly better DFS and OS for SCC cases. This result may be justified by higher percentage of LN involvement within TCC group ( 32\%) compared to $20 \%$ in the SCC group. Moreover, $50 \%$ of TCC tumours' were of high grade tumour as opposed to only $18 \%$ of SCC tumours'.

The beneficial effect of PORT was proved in a large prospective randomized trial at NCI Cairo, including 236 
patients, for locally advanced bladder cancer patients. The 5 year LC rates were $87 \% \pm 4 \%$ and $93 \% \pm 3 \%$ for hyperfractionated (HF) and conventional (CF) PORT compared to $50 \% \pm 6 \%$ for the cystectomy alone group. This effect was consistent across all tumour types, grades and pathologic stages whether or not the lymph nodes were involved. The 5-year LC rates for pT3a, pT3b and pT4a were $96 \%, 91 \%$ and $74 \%$ respectively [8]. These results were replicated in nonrandomized controlled Radiation Therapy Oncology Group (RTOG) trials, [25] and other Egyptian and non-Egyptian series (for patients having TCC, SCC and adenocarcinoma); where the DFS rates ranged between 45\% - 79\% while LC ranged between 79\% - 97\% [9] [26]. Depending on these results, the routine work at NCI Cairo was to give PORT for bladder cancer patients with T-stage $\geq$ pT2b or node positive cases. In an attempt to evaluate our work results, this study was conducted to re-evaluate this protocol regarding its effect on prognosis and complications. In the present study, LC rates were rather high representing 93\% at 5 years, similar to results described by Zaghloul et al. 1992 [8].

A study of 442 patients performed to assess the factors affecting local failure after RC (130 patients out of 442 received adjuvant/neoadjuvant chemotherapy) proved that SM status and the extent of lymph node dissection strongly affected the LC rates with 5year LC rate of $86 \%$ vs. $58 \%$ for negative and positive SM respectively. As for the extent of LN dissection, the 5 year LC rate was $86 \%$ for $\geq 10$ nodes vs. $69 \%$ for $<10$ nodes dissection [12]. The current study also proved that the SM status and extent of LN dissection are significant prognostic factors but with even higher LC rates than the aforementioned study. The 5 year LC rates for margin status and extent of LN dissection were $95 \%$ vs. $77 \%$ for negative and positive margins respectively and $96 \%$ vs. $90 \%$ for $\geq 10$ and $<10 \mathrm{LN}$ dissection respectively. These superior rates may be attributed to the effect of PORT in improving LC rates regardless of the pathologic stage, SM status or even extent of LN dissection.

With reference to the $\mathrm{T}$ stage, the current study demonstrated more inferior OS associated with more advanced T stage with 5 year OS of 73\% with pT2b, $40 \%$ with pT3 and 19\% with pT4a patients. This data was in accordance with Zaghloul et al. 2010 [27]. However, there was no difference in OS for N1 and N2 patients with a rate of $\sim 36 \%$ at 5 years for both groups. This result was different from rates reported in Ghoneim et al. 2008 study [28], with 5 year OS of $44 \%$ for N1 and $27 \%$ for N2 patients. This difference may be due to the fact that $62 \%$ of N1 patients had grade 3 disease compared to $41 \%$ in N2 patients. Also, only $14 \%$ of N1 patients had organ confined disease versus $23 \%$ in N2 patients, which probably improved survival rates in the N2 group.

Post-operative radiotherapy in bladder cancer remains unpopular owing to the fear of late intestinal complications. Warning results were published by Reisinger et al. 1992 [9] as they reported a 37\% (15 out of 40 patients) rate of intestinal obstruction in patients who received PORT. Nine out of these 15 patients required surgery and three died. On the contrary, Zaghloul et al. 1992 [8] had 14 out of the 78 patients (18\%) treated with CF PORT and four out of the 75 patients (5\%) treated with HF PORT, who experienced chronic enteritis of different grades. Only three (4\%) and four (5\%) out of the CF and HF patients, respectively, progressed to fistula that necessitated surgery. Similar levels of complications were experienced by adenocarcinoma patients treated with PORT in a nonrandomized study comprising 192 patients after RC and pelvic lymphadenectomy [29]. The difference in late sequalae between the latter two studies and that of Reisinger et al. was probably due to the larger volume of radiation used in the Reisinger et al. study (upper border at fourth Lumbar vertebrae) or the biologically higher dose reaching intestine as patients were given 500 cGy sngle dose preoperatively followed by 4000 - 4500 cGy CF postoperatively, which led to severe late bowel complications. With reference to the radiation toxicity in the current study, 71\% (148 patients) suffered from small bowel reactions (diarrhea/abdominal colic) mostly of grade 1 and 2 intensity with 55\% and 43\% respectively. Bleeding per rectum was encountered in only 4 patients (3\%). Grade 4 early bowel reactions were not experienced in any of the 208 patients. As for the late toxicity, $24 \%$ suffered late reactions; lower limb edema, scrotal swelling, ureteric stricture. Only 6 patients (3\%) suffered from intestinal obstruction (Two patients were treated conservatively, 2 patients underwent surgical exploration, 1 patient died and 1 patient had lost follow up). A figure which is much less than those seen in Reisenger et al. study and claiming continuous benefit of PORT with low complications that was seen in Zaghloul et al. study [8] [29].

\section{Conclusion and Recommendation}

This study supports that postoperative radiotherapy for selected group of patients, significantly improves local control with tolerable toxicities. With the modern radiotherapy techniques and improved normal tissue sparing, we recommend more investigation with adjuvant radiotherapy following RC with the addition of chemotherapy. 


\section{References}

[1] Griffiths, T.R.L. (2013) Current Perspectives in Bladder Cancer Management on Behalf of Action on Bladder Cancer. International Journal of Clinical Practice, 65, 435-448.

[2] Ploeg, M., Aben, K.K. and Kiemeney, L.A. (2009) The Present and Future Burden of Urinary Bladder Cancer in the World. World Journal of Urology, 27, 289-293. http://dx.doi.org/10.1007/s00345-009-0383-3

[3] Bolenz, C., Ho, R., Nuss, G.R., et al. (2010) Management of Elderly Patients with Urothelial Carcinoma of the Bladder: Guideline Concordance and Predictors of Overall Survival. BJU International, 106, 1324-1329. http://dx.doi.org/10.1111/j.1464-410X.2010.09417.x

[4] Stein, J.P. and Skinner, D.G. (2006) Radical Cystectomy for Invasive Bladder Cancer: Long-Term Results of a Standard Procedure. World Journal of Urology, 24, 296-304. http://dx.doi.org/10.1007/s00345-006-0061-7

[5] Abol-Enein, H., et al. (2005) Neoadjuvant Chemotherapy for Invasive Bladder Cancer. Cochrane Database of Systematic Reviews, Article ID: CD005246.

[6] Pollack, A., Zagars, G.K., Cole, C.J., et al. (1995) The Relationship of Local Control to Distant Metastasis in Muscle Invasive Bladder Cancer. Journal of Urology, 154, 2059-2063. http://dx.doi.org/10.1016/S0022-5347(01)66693-X

[7] Ide, H., Kikuchi, E., Miyajima, A., et al. (2008) The Predictors of Local Recurrence after Radical Cystectomy in Patients with Invasive Bladder Cancer. Japanese Journal of Clinical Oncology, 38, 360-364. http://dx.doi.org/10.1093/jico/hyn036

[8] Zaghloul, M.S., Awwad, H.K., Akoush, H.H., et al. (1992) Postoperative Radiotherapy of Carcinoma in Bilharzial Bladder: Improved Disease Free Survival through Improving Local Control. International Journal of Radiation Oncology*Biology*Physics, 23, 511-517. http://dx.doi.org/10.1016/0360-3016(92)90005-3

[9] Reisinger, S.A., Mohiuddin, M. and Mulholland, S.G. (1992) Combined Pre- and Postoperative Adjuvant Radiation Therapy for Bladder Cancer a Ten Year Experience. International Journal of Radiation Oncology*Biology*Physics, 24, 463-468. http://dx.doi.org/10.1016/0360-3016(92)91060-Z

[10] Zaghloul, M.S., Awwad, H.K., Soliman, O., et al. (1986) Postoperative Radiotherapy of Carcinoma in Bilharzial Bladder Using a Three-Fractions per Day Regimen. Radiotherapy Oncology, 6, 257-265. http://dx.doi.org/10.1016/S0167-8140(86)80192-X

[11] Spera, J.A., Whittington, R., Littman, P., Solin, L.J. and Wein, A.J. (1988) A Comparison of Preoperative Radiotherapy Regimens for Bladder Carcinoma. The University of Pennsylvania Experience. Cancer, 61, 255-262. http://dx.doi.org/10.1002/1097-0142(19880115)61:2<255::AID-CNCR2820610210>3.0.CO;2-X

[12] Baumann, B.C., Guzzo, T.J., He, J., Keefe, S.M., Tucker, K., Bekelman, J.E., Hwang, W.T., Vaughn, D.J., Malkowicz, S.B. and Christodouleas, J.P. (2013) A Novel Risk Stratification to Predict Local-Regional Failures in Urothelial Carcinoma of the Bladder after Radical Cystectomy. International Journal of Radiation Oncology * Biology * Physics, 85, 81-88.

[13] Herr, H.W., Faulkner, J.R., Grossman, H.B., Natale, R.B., de Vere White, R., Sarosdy, M.F. and Crawford, E.D. (2004) Surgical Factors Influence Bladder Cancer Outcomes: A Cooperative Group Report. Journal of Clinical Oncology, 22, 2781-2789. http://dx.doi.org/10.1200/JCO.2004.11.024

[14] Zaghloul, M.S., Mohran, T.Z., Saber, R.A. and Agha, N. (2002) Postoperative Radiotherapy in Bladder Cancer. Journal of the Egyptian National Cancer Institute, 14, 161-168.

[15] Cox, J.D., Stetz, J. and Pajak, T.F. (1995) Toxicity Criteria of the Radiation Therapy Oncology Group (RTOG) and the European Organization for Research and Treatment of Cancer (EORTC). International Journal of Radiation Oncology * Biology * Physics, 31, 1341-1346. http://dx.doi.org/10.1016/0360-3016(95)00060-C

[16] Dawson, B. and Trapp, R.G., Eds. (2004) Basic and Clinical Biostatistics. 4th Edition, McGraw-Hill Professional, New York.

[17] Ibrahim, A.S., Khaled, H.M., Mikhail, N.N., Baraka, H. and Kamel, H. (2014) Cancer Incidence in Egypt: Results of the National Population-Based Cancer Registry Program. Journal of Cancer Epidemiology, 2014, Article ID: 437971. http://dx.doi.org/10.1155/2014/437971

[18] Efstathiou, J.A., Zietman, A.L., Coen, J.J. and Shipley, W.U. (2012) Chapter 52: Bladder Cancer. In: Gunderson, L.L. and Tepper, J.E., Eds., Clinical Radiation Oncology, Third Edition, Elsevier, Amsterdam, 1000-1123.

[19] Gouda, I., Mokhtar, N., Bilal, D., El-Bolkainy, T. and El-Bolkainy, N.M. (2007) Bilharziasis and Bladder Cancer: A Time Trend Analysis of 9843 Patients. Journal of the Egyptian National Cancer Institute, 19, 158-162.

[20] Tracey, E., Roder, D., Luke, C. and Bishop, J. (2009) Bladder Cancer Survivals in New South Wales, Australia: Why Do Women Have Poorer Survival than Men? BJU International, 104, 498-504. http://dx.doi.org/10.1111/j.1464-410X.2009.08527.x

[21] Shariat, S.F., Sfakianos, J.P., Droller, M.J., Karakiewicz, P.I., Meryn, S. and Bochner, B.H. (2010) The Effect of Age 
and Gender on Bladder Cancer: A Critical Review of the Literature. BJU International, 105, 300-308. http://dx.doi.org/10.1111/j.1464-410X.2009.09076.x

[22] May, M., Stief, C., Brookman-May, S., Otto, W., Gilfrich, C., Roigas, J., et al. (2012) Gender-Dependent Cancer-Specific Survival Following Radical Cystectomy. World Journal of Urology, 30, 707-713. http://dx.doi.org/10.1007/s00345-011-0773-1

[23] Otto, W., May, M., Fritsche, H.M., Dragun, D., Aziz, A., Gierth, M., et al. (2012) Analysis of Sex Differences in Cancer-Specific Survival and Perioperative Mortality Following Radical Cystectomy: Results of a Large German Multicenter Study of Nearly 2500 Patients with Urothelial Carcinoma of the Bladder. Gender Medicine, 9, 481-489. http://dx.doi.org/10.1016/j.genm.2012.11.001

[24] Balci, U., Ozer, K., Gorgel, S.N., Sefik, E., Girgin, C. and Dincel, C. (2013) Do Pure Squamous Cell Carcinomas and Urothelial Carcinomas Have Similar Prognosis after Radical Cystectomy? World Journal of Urology, 31, 1177-1182. http://dx.doi.org/10.1007/s00345-012-0872-7

[25] Cozzarini, C., Pelegrini, D., Fallini, M., Mandelli, D., Rosso, A., Bertini, R., et al. (1999) Reappraisal of the Role of Adjuvant Radiotherapy in Muscle-Invasive Transitional Cell Carcinoma of the Bladder. International Journal of Radiation Oncology * Biology * Physics, 45, 221-222. http://dx.doi.org/10.1016/S0360-3016(99)90162-1

[26] Zaghloul, M.S., El Baradie Nouh, M.A., Abdel-Fatah, S., Taher, A. and Shalaan, M. (2007) Prognostic Index for Primary Adenocarcinoma of the Urinary Bladder. Gulf Journal of Oncology, 1, 47-54.

[27] Zaghloul, M. (2010) Adjuvant and Neoadjuvant Radiotherapy for Bladder Cancer: Revisited. Future Oncology, 6, 1177-1191. http://dx.doi.org/10.2217/fon.10.82

[28] Ghoneim, M.A., Abdel-Latif, M., El-Mekresh, M., Abol-Enein, H., Mosbah, A., Ashamallah, A. and el-Baz, M.A. (2008) Radical Cystectomy for Carcinoma of the Bladder: 2,720 Consecutive Cases 5 Year Later. Journal of Urology, 180, 121-127. http://dx.doi.org/10.1016/j.juro.2008.03.024

[29] Zaghloul, M.S., Nouh, A., Nazmy, M., Ramzy, S., Zaghloul, A.S., Sedira, M.A. and Khalil, E. (2006) Long-Term Results of Primary Adenocarcinoma of the Urinary Bladder: A Report on 192 Patients. Urologic Oncology, 24, 13-20. http://dx.doi.org/10.1016/j.urolonc.2005.05.027 